\title{
Treatment of produced water from Niger Delta oil fields using simultaneous mixture of local materials
}

\author{
S. G. Udeagbara ${ }^{1} \cdot$ S. O. Isehunwa ${ }^{2} \cdot$ N. U. Okereke ${ }^{3} \cdot$ I. U. Oguamah ${ }^{3}$
}

Received: 3 July 2020 / Accepted: 6 October 2020 / Published online: 22 October 2020

(c) The Author(s) 2020

\begin{abstract}
Produced water (PW) from petroleum reservoirs often contains heavy metals and other contaminants that are harmful to the environment. Most of the commonly used treatment techniques have been reported to be ineffective in reducing some of the contaminants' concentrations to recommended disposal levels. This study evaluated the effectiveness of four selected bioadsorbents combined for treating PW from Niger Delta oil fields. In this study, orange peels (I), banana peels (II), sponge gourd (Luffa cylindrica) (III) and palm kernel fibers (IV) were washed with distilled water, sun-dried ( $24 \mathrm{~h})$ and dried in the oven at $105 \pm 5{ }^{\circ} \mathrm{C}(3 \mathrm{~h}, \mathrm{I}$ and II $), 150{ }^{\circ} \mathrm{C}(30 \mathrm{~min}, \mathrm{III})$ and $80{ }^{\circ} \mathrm{C}(3 \mathrm{~h}, \mathrm{IV})$. They were ground into powder, sieved $(150 \mu$, Group A) and ( $300 \mu$, Group B), washed with $0.4 \mathrm{~mol} / \mathrm{L} \mathrm{HNO}_{3}$, filtered and rinsed with distilled water. Samples of PW were obtained from fields R, X, and Y in the Niger Delta and analysed for heavy metals using an atomic absorption spectrophotometer (AAS). Samples were treated in adsorption column over $6 \mathrm{~h}$ using the adsorbents simultaneously. Treated samples were analysed with AAS and characterised. Adsorption of heavy metals were assessed using Langmuir and Freundlich models. Data were analysed using regression and other statistical methods. For the $150 \mu$ size of sample R, the percentage reductions for the metal concentrations ( $\mathrm{Pb}, \mathrm{Ni}, \mathrm{Cd}, \mathrm{Cu}, \mathrm{Fe}, \mathrm{Mg}, \mathrm{Cr}, \mathrm{Zn}, \mathrm{Mn}, \mathrm{Ca}, \mathrm{Ar}, \mathrm{B}, \mathrm{Sn}$ and $\mathrm{Ba}$ ) were found to be $100 \%$, $52.7 \%, 100 \%, 100 \%, 85.87 \%, 19.48 \%, 100 \%, 92.8 \%, 17.74 \%, 98.86 \%, 22.32 \%, 29.56 \%, 78.06 \%$ and $44.74 \%$, respectively, while the reduction in $300 \mu$ size were $1.52 \%, 97.2 \%, 71.4 \%, 17.1 \%, 43.8 \%, 45.6 \%, 7.04 \%, 89.6 \%, 35.4 \%, 99.6 \%, 0.0001 \%$, $1.19 \%, 14.19 \%$ and $0.002 \%$, respectively. The finer adsorbents were more effective. Similar results were obtained for PW samples from the other fields. Produced water from Niger Delta oil fields was effectively treated of contaminants using four selected bio-adsorbents mixed simultaneously.
\end{abstract}

Keywords Produced water $\cdot$ Heavy metals adsorption $\cdot$ Adsorption isotherms $\cdot$ Bio-adsorbents

\section{Introduction/background of the study}

The largest waste stream from oil field operations is produced water. Production across the globe is estimated at over 60 million barrels per day. The volume of oil produced from each petroleum reservoir depends on factors such as geological structure, petrophysics, reservoir drive mechanism,

N. U. Okereke

ndubuisi.okereke@futo.edu.ng

1 Department of Petroleum Engineering, Afe Babalola University, Ado-Ekiti, Nigeria

2 Department of Petroleum Engineering, University of Ibadan, Oyo, Nigeria

3 Department of Petroleum Engineering, Federal University of Technology, Owerri, Nigeria depletion stage, well completion method and production practices (Isehunwa and Onovae 2011).

Produced water management has become very important because of the volume involved, cost of treatment and environmental impact of entrapped chemicals. Many oil producing countries have therefore made laws and guidelines on the quality of produced water to be discharged.

In the early days of crude oil extraction from the subsurface, little or no effort was made in handling produced water. In some situations it was discharged to water bodies with little or no form of treatment, spilled on ground surface, or placed in underground pits to evaporate or soak into the subsurface. As time went on, petroleum engineers realized that water injection into the oil reservoirs could enhance production (Gregory et al. 2011). 


\section{Crude oil processing}

Crude oil-gas-water mixtures that are extracted from reservoirs are passed through flow lines and manifold system, to a treatment facility called the gas-oil separation system. The first stage in the treatment and processing of the well stream is the separation of the oil, gas and water into separate components. This occurs in a two-phase gas-oil separators when the well stream contains no water or in a three-phase separators when water is involved. Well stream separation carried out in these separators is the main process in a train of oil field processing units. The separators are meant to reduce the excessive pressure as a result of gas associated with the produced well crude and, subsequently, separating the gas from the oil. When water is involved in the well stream, separators as well separate the free water from the crude oil. Once separation is achieved, the entire streams separately undergoes more processing and treatment for further field treatment, as highlighted in Fig. 1.

Crude oil emanating from the separator does not meet the purchaser's specifications and requirements. The crude oil might still contains about $9 \%$ and $14 \%$ water that exists as emulsified water. The presence of this emulsified water causes corrosion and scaling problems in transportation and processing operations. Water left in the crude oil is called basic sediments and water (BS\&W). A maximum of $1 \% \mathrm{BS} \& \mathrm{~W}$ is acceptable in most cases. The limit on the salt content of the residual water in crude oil is usually between 10 and 15 PTB (pounds of salt per thousand barrels of crude oil). If these requirements are not met at the end, then more treatment of the crude oil emanating from the separator will be needed. Such treatment includes emulsion treatment/dehydration and desalting processes. After crude oil treatment, it may be a necessary to stabilize the crude oil to optimize the oil recovery and minimize its volatility. Most produced crude oils contain hydrogen sulfide and other sulfur compounds. Sour crude oil typically contains total sulfur content $>0.5 \%$ by weight. Sour crude oils have safety as well as corrosion problems. Further treatment called sweetening process will be needed to eliminate hydrogen sulfide or reduce its content to a certain limits (Abdel-Aal et al. 2003).

\section{Three-phase oil-water-gas separation}

Water produced with the oil exists mostly as free water and most times as water-in-oil emulsion. Sometimes, when the water-oil ratio is much, oil-in-water rather than water-in-oil emulsion will form. Free water extracted with the crude oil from the reservoir is defined as the water that will separate

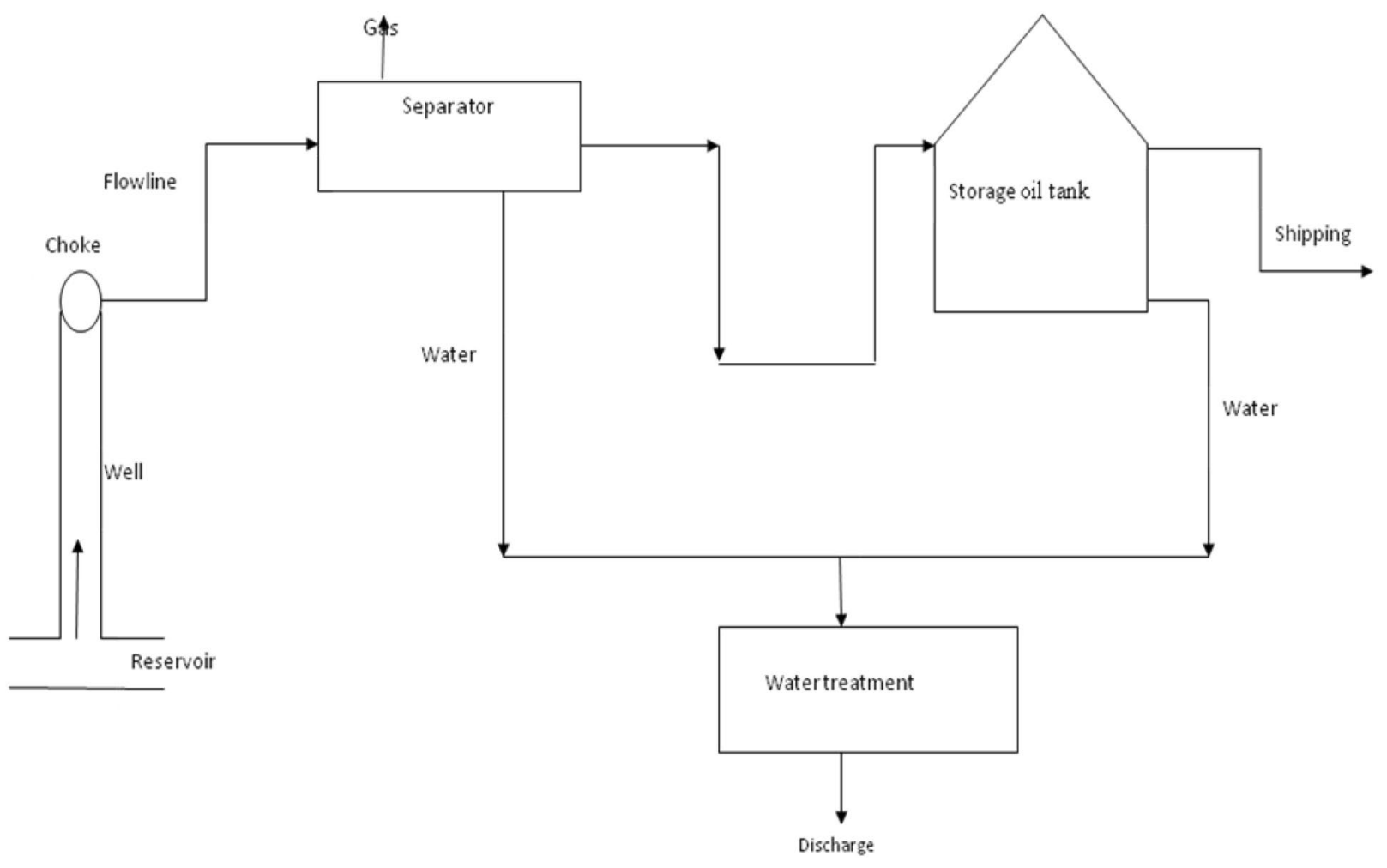

Fig. 1 An outline of the processing surface field operations 
out and settle from the oil by gravity. In separating the emulsified water, treatment via chemicals, electrostatic treatment, as well as heat treatment, or a combination of them will be needed in addition to gravity settling. Apart from water and oil, gas will always be involved and must be separated from the liquid (water and oil). The quantity of gas depends mostly on the producing and separation conditions. When the quantity of gas is small compared to the quantity of liquid, the method applied to separate free water, oil and gas is known as free water knockout. Under this condition, the separation of the water from the crude oil will guide the design of the apparatus. When there is a larger quantity of gas to be separated from the oil and water, the vessel is known as three-phase separator and either the gas volume requirements or the water-oil separation constraints may guide the vessel design. Figure 2 is an example of a gravitybased three-phase separator; highlighting the gravity settling section, oil and emulsion section as well as the water and oil separation outlet at the lower section of the vessel and the gas outlet at the upper section of the separator.

This current work is focused on evaluating the potential of four adsorbents applied simultaneously in treating produced water. The aim of this study was to reduce the concentration of heavy metals and other contaminants from produced water obtained from Niger Delta oil fields. Specific objectives include; design of adsorption column, treatment of produced water samples with selected bio-adsorbents in the adsorption chamber to reduce heavy metals concentration and other organics present. The methodology of the work involved experimental analysis of four selected

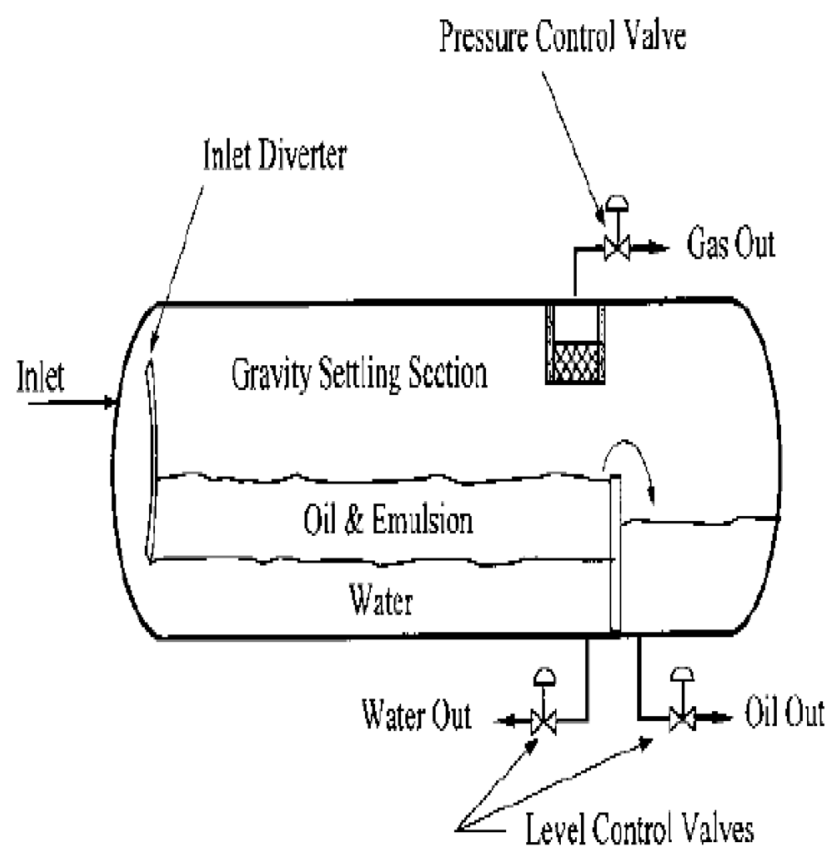

Fig. 2 Horizontal three-phase separator (Abdel-Aal et al. 2003) bio-adsorbents for produced water treatment over three samples of produced water from three different oil fields.

\section{Literature review}

In this section of the paper, focus was on reviewing existing produced water treatment techniques; in order to identify key challenges and areas of improvement necessitating the current work.

\section{Emulsion treatment and dehydration of crude oil}

The multiphase stream produced at the wellhead often consists of gas oil and water mixtures. The gaseous and water contents produced at the wellhead must be removed; while the gaseous components are removed via the separators, the produced water in all its form must be removed by a dehydration process. The removal of the water content of the produced fluid mixture at the wellhead depends on the amount of water in the mixture, the salinity as well as the dehydration process used. Field treatment of water can produce oil with minimal water content up to 0.2 and 0.5 of $1 \%$. The water that remains after the oil has undergone a dehydration is classified as part of the bottom sediments and water (BS\&W). The process of treatment and facilities should be carefully selected and designed to meet the contract requirement for BS\&W. Care should be taken not to exceed the target oil dryness. Discharge of more remnant water than allowed by contract costs more money while generating less income because the volume of oil sold will be based on the contract value of the BS\&W (Khaled et al. 2011).

The basic principles for the treatment process includes:

1. The breaking of the emulsion, which could be achieved by either heating, chemical addition or a combination of addition of heat, the addition of chemicals, and the application of electrostatic field

2. Coalescence of tiny and smaller water droplets into larger droplets

3. Settling, by gravity, and removal of free water.

\section{Oil emulsions}

Oil extraction from the reservoirs hardly takes place without water accompanying the oil to the surface. Salt water is extracted alongside oil in different forms and methods as illustrated in Fig. 3. Apart from free water, emulsified water (water-in-oil emulsion) is the one form that generates much issue in the dehydration of crude oil. Oil emulsion is simply a mixture of oil and water. Generally, an emulsion can be seen as a mixture of two immiscible liquids, of which one is dispersed as droplets in the other (the continuous phase), and

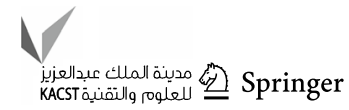




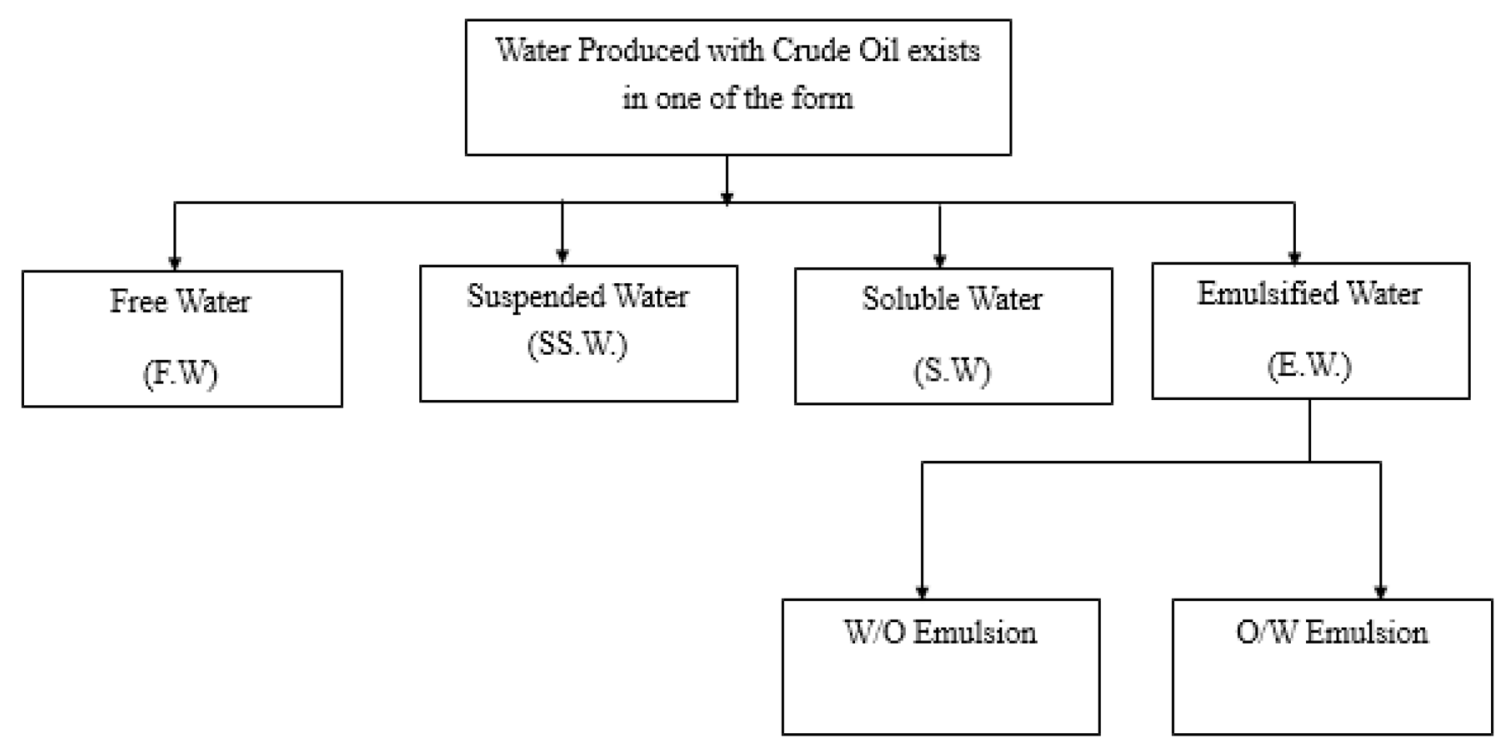

Fig. 3 Forms of saline water produced with crude oil (Abdel-Aal et al. 2003)

is stabilized by an emulsifying agent. In the oil reservoirs, crude oil and water are formed as the two immiscible phases together. They form water-in-oil emulsion (W/O emulsion), in which water is dispersed as small droplets in the oil. This is identified as type $\mathrm{C}$ in Fig. 4. However, as a spike in the water cut comes up, the possibility of forming reverses emulsions (oil-in-water, or $\mathrm{O} / \mathrm{W}$ emulsion) increases. This is type B in Fig. 4.

\section{Options available for managing produced water}

In produced water management, some of the available options to the oil and gas operators include (Igunnu and Chen 2014):

Fig. 4 Schematic representation of a non-dispersed system, $\mathbf{b}$ an $\mathrm{O} / \mathrm{W}$ emulsion, and $\mathbf{c}$ a W/O emulsion (Abdel-Aal et al. 2003)

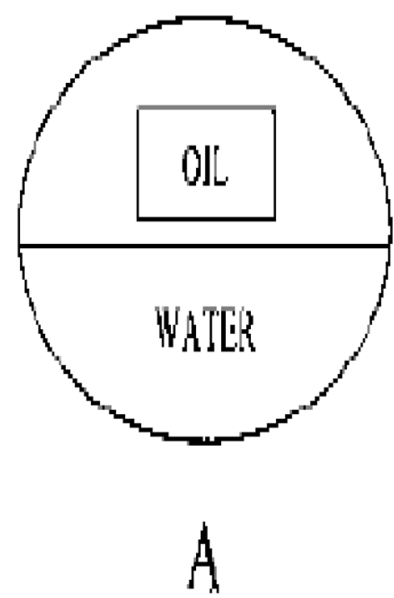

1. Prevent the production of water unto surface facilityusing separators downhole which separate water from gas and oil stream and re-inject it into suitable formation.

2. Injection of produced water-this involves re-injection of produced water into the same formation or other suitable formation; it includes the conveyance of the produced water from the production to the injection site and proper purification of the produced water before injection in order to reduce fouling and scaling agents and possible bacteria growth.

3. Produced water discharge-involves treatment of produced water to meet onshore or offshore discharge regulations. Although, some locations do not require treatment before discharge.
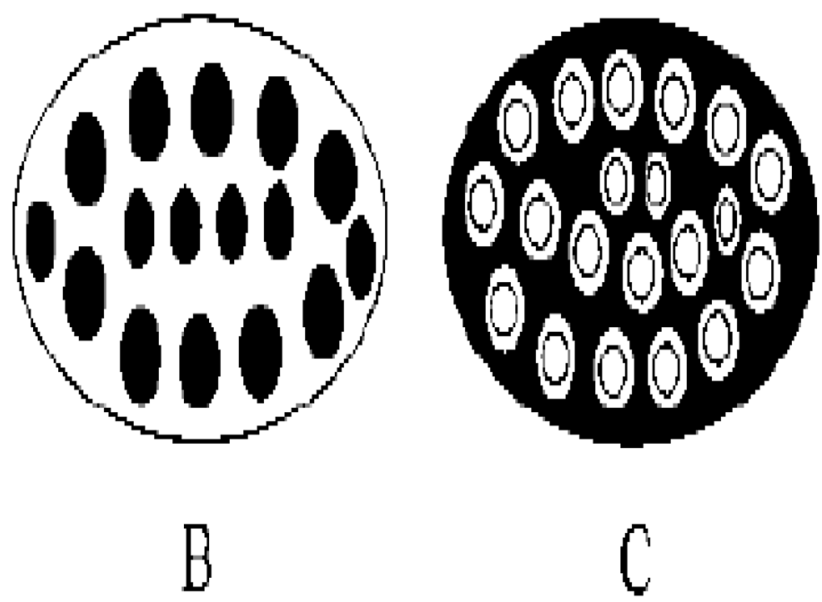
4. Re-use of wastewater for oil field operations-involving the treatment of produced water to meet the required quality for drilling and work-over operations.

5. Used to support other multi-purpose benefits-in some instances, important treatment of produced water is a crucial requirement in order to meet required quality for important benefits such as irrigation, arable land restoration, cattle and animal consumption and drinking water for human consumption.

Water produced during oil and gas production operations constitutes the most prominent waste in the oil industry. The produced water varies both in quality and quantity. Sometimes, the water could be a useful by-product or even a marketable commodity. Produced water is often considered a waste, but the oil industry is beginning to know that this waste water is a potential profit stream. Considering produced water as either a waste or commodity has its cost implication, which needs to be managed in-accordance with the specific objectives of each production project and also depending on the region (Fakhru'lRazi et al. 2009). If this is not well addressed, the life of the well could be adversely affected, thereby, leading to huge recoverable reserves being left in the ground. Industry practice on the management of produced water must also protect the environment or the operator could be fined by regulatory authorities. The methodology for managing produced water is a function of the composition of the produced water, the location of the asset in consideration, the volume of reserves and the facilities available in the asset (Gregory et al. 2011).

El-Din et al. (2018) carried out a research work on the potential use of aquatic plant for produced water purification. The aquatic plants used in their research were duckweeds, water hyacinth as well as green algae (Chlorella vulgaris). The plants were prepared and treated before use for the produced water treatment Ahmed et al. (2016); Annadural and Lee (2012). The parameters considered in their research were chemical oxygen demand (COD), biological oxygen demand (BOD). According to their result, $\mathrm{COD}$ and BOD were reduced in the produced water by ( $43 \%$ and $42 \%$ ) by duckweed, $28 \%$ and $33 \%$ by water hyacinth and $33 \%$ and $38 \%$ by green algae from the results, duckweeds have higher pollutants removal efficiency than other plants. The limitation of this method is the unavailability of the plants locally within Nigeria.

Aclione et al. (2018), reviewed produced water main treatment technologies. The review was based on the increasing production of oily water and its treatment challenge due to the complexity and volume of water generated, because this undesirable effluent requires treatment before its final disposal in order to meet the legal requirement for disposal in the environment or technical requirements for injection into oil wells. The review highlighted not only for more efficient removal and recovery of oils and other toxic agents, but also financial viability along these technology.

Rasheed et al. (2019) carried out a research on the evaluation of the efficiency of char and biochar for waste water treatment. Char and biochar are carbon rich compounds obtained from pyrolysis. The heavy metals targeted in the waste water were chromium, iron, zinc, nickel, lead and manganese Ahalya et al. (2005); Allen and Brown (2004). From their results, it was concluded that the efficiency of biochar in treating waste water is much better as compared to char as the reduction in heavy metals values were significant with biochar. According to them, biochar could be used as a sorbent for wastewater remediation.

Some other contemporary existing and proposed methods of produced water treatment include the use of membrane technology, the use of novel fibrous coalescence technique, biological treatment in membrance-bioreactors, application of thermal evaporators and the deployment of a novel settling tank for produced water treatment Alzahrani and Mohammad (2014), Dores et al. (2012), Lu et al. (2019) and Shah et al. (2019).

This current study focused on evaluating the potential of four adsorbents applied simultaneously for the treatment of produced water.

\section{Materials and methods}

The materials used in this research work were: produced water samples from Niger delta oil fields, Luffa cylindrica (sponge gourds), banana peels, orange peels, palm kernel fiber, chemical reagents, filter paper and glass wares, etc. The equipment used were: milling machine, adsorption column, mechanical shaker, oven, atomic absorption spectrophotometer, weighing balance, $\mathrm{pH}$ meter, refrigerator and sieves, etc. The heavy metals analyzed were lead (pb), nickel $(\mathrm{Ni})$, cadmium $(\mathrm{Cd})$, copper $(\mathrm{Cu})$, iron $(\mathrm{Fe})$, magnesium $(\mathrm{Mg})$, chromium $(\mathrm{Cr})$, zinc $(\mathrm{Zn})$, calcium (ca), Boron (B), Tin ( $\mathrm{Sn}$ ), arsenic (As) and Manganese (Mn) as well as Barium $(\mathrm{Ba})$ and some other contaminants in the produced water samples such as: carbonates, bi-carbonate and acidic components, etc.

\section{Collection of samples and materials}

Samples of produced water were collected from four different oil fields in the Niger Delta area. Sample R was collected from Imo River oil field in Rivers State; Sample X was collected from Nembe oil field in Bayelsa State, sample $\mathrm{Y}$ was from Kolo creek oil field in Rivers/Bayelsa State. The adsorbents (Banana peels, Orange peels, Luffa cylindrica) were purchased from a local market in Ado-Ekiti, Nigeria

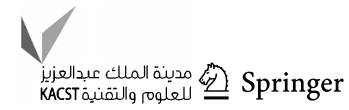


and the palm-kernel fiber was collected from ABUAD farm in Ado-Ekiti, Ekiti state. Chemicals such as: nitric acid, hydrochloric acid, sodium sulphate, phenolphthalein and sulphric acid as well as other reagents used were of analytical and standard grade.

Figure 5 captures the Luffa cylindrical and palm kernel fiber samples, which were used for the treatment of the produced water samples obtained from the oil field.
In Fig. 6, banana peels and raw orange peels also used for the treatment of the produced water samples are also captured.

Figure 7 captures some of the produced water samples and filtrates from adsorption process, as samples for the experiment conducted.

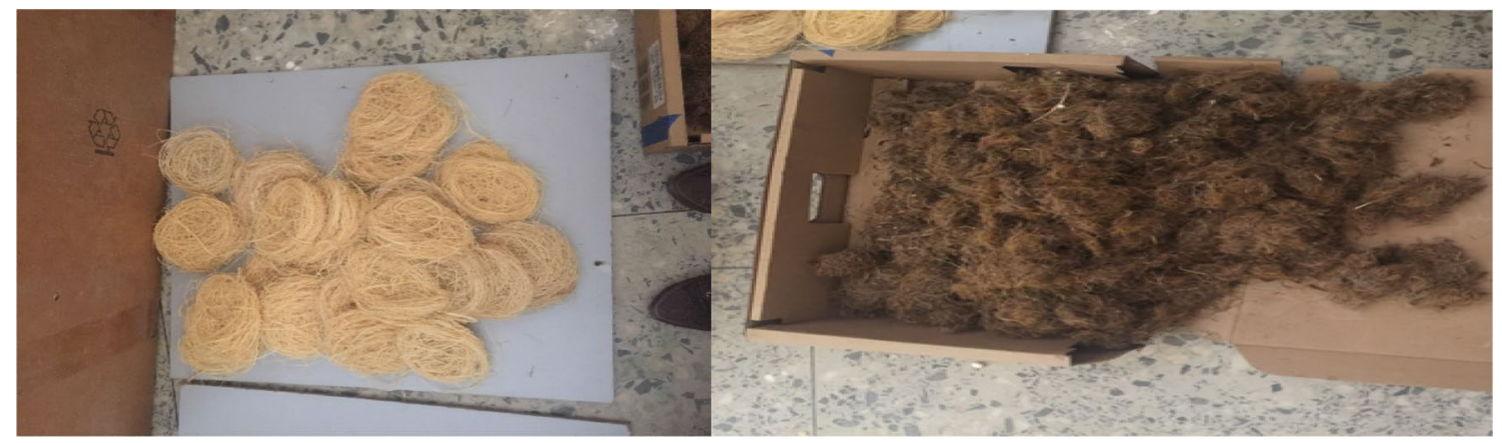

Fig. 5 Luffa cylindrica and palm kernel fiber

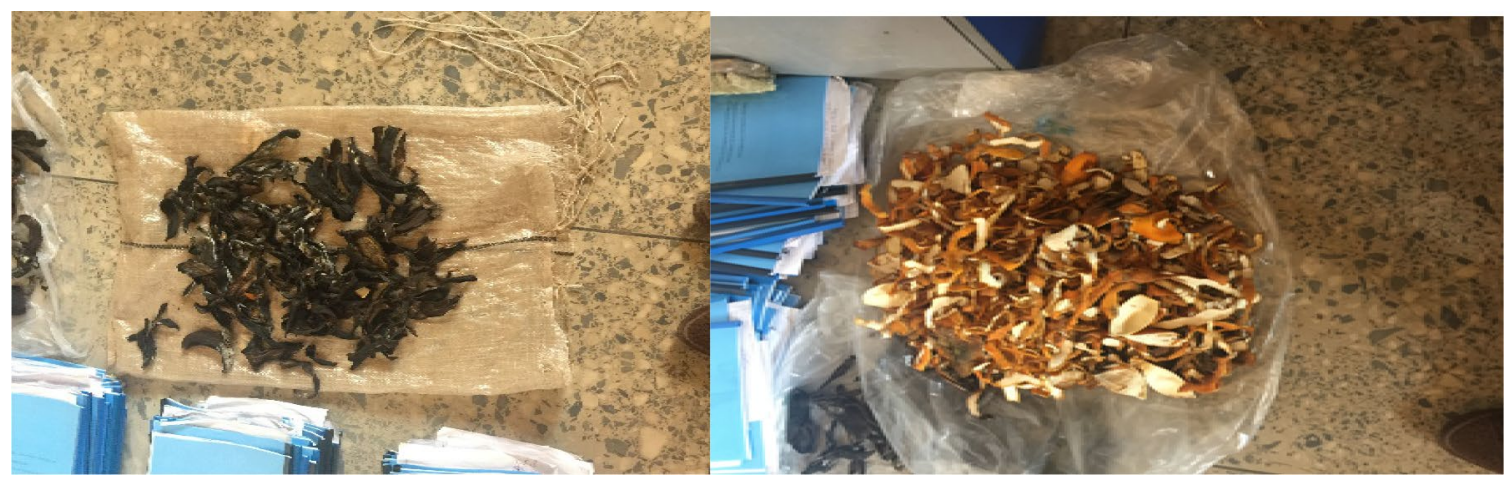

Fig. 6 Banana peels and raw orange peels
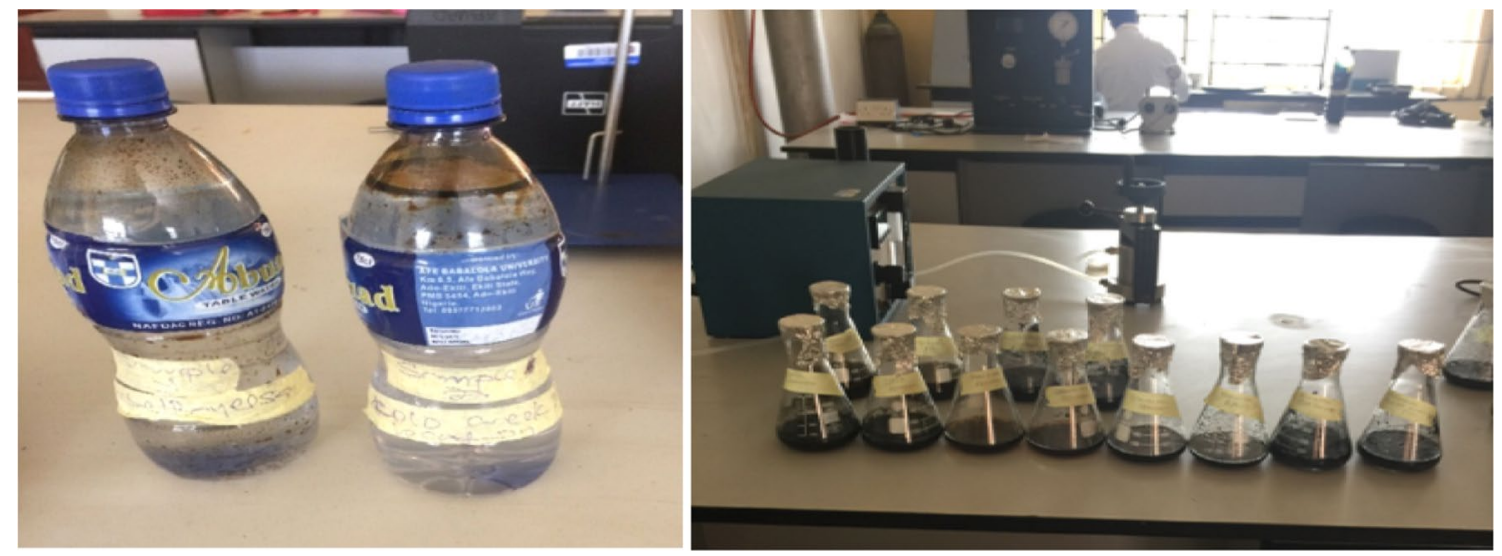

Fig. 7 Produced water samples and filtrates from adsorption process 


\section{Preparation of banana peels, orange peels, Luffa cylindrica, palm kernel fiber and the experimental procedure}

The adsorbents were prepared by washing them thoroughly with distilled water to remove any dirt that may be stuck on it. They were then cut into pieces, for easy handling; suns dried ( $24 \mathrm{~h}$ during hammer time period), and were finally dried in an oven at $105{ }^{\circ} \mathrm{C}$ for $3 \mathrm{~h}$ for banana and orange peels, $150{ }^{\circ} \mathrm{C}$ for $30 \mathrm{~min}$ for Luffa cylindrica, and $80^{\circ} \mathrm{C}$ for $3 \mathrm{~h}$ for palm kernel fibre.

\section{Simultaneous mixture of the adsorbents in the adsorption column}

After drying, the adsorbents were crushed using the milling machine and were sieved with the mechanical shaker

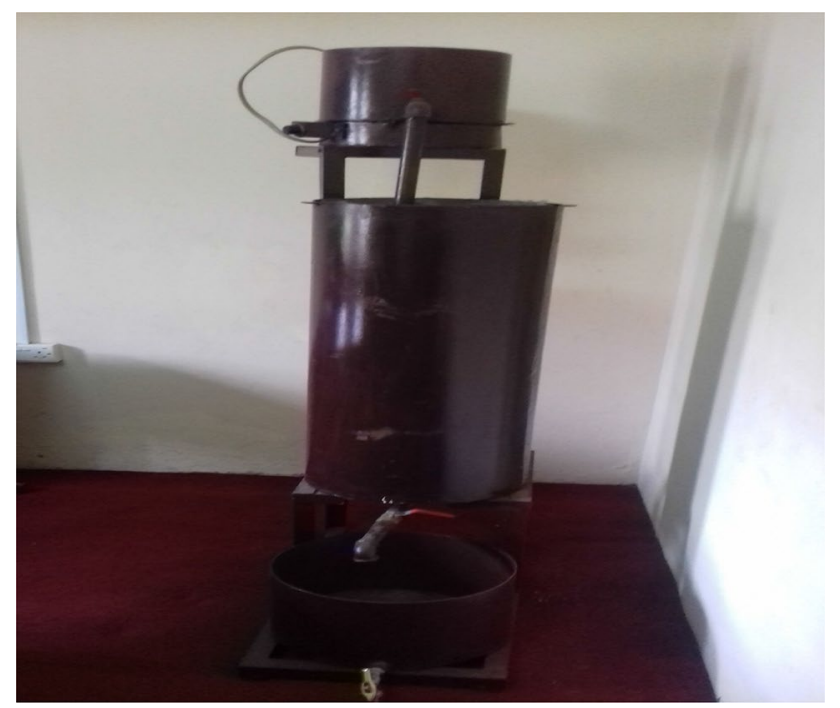

Fig. 8 The adsorption chamber using mesh size of 150 and $300 \mu$. The sieved samples were treated separately with $200 \mathrm{~mL}$ of $0.4 \mathrm{~mol} / \mathrm{L} \mathrm{HNO}_{3}$ for $24 \mathrm{~h}$. After which they were filtered and rinsed with distilled water until the filtrate was near neutral. 2-Gram each of the $150 \mu$ particle size of the four (4) adsorbents was measured to sum up to 8 -g in total. The adsorbents were mixed together simultaneously at a ratio of 1:1:1:1 within the adsorption column. $250 \mathrm{~mL}$ of sample $\mathrm{R}$ (produced water) was flown through the adsorption column containing the adsorbents to allow adsorption to take place. The filtrate was collected at an interval of $2 \mathrm{~h}$ and was subjected to analysis using AAS to determine the concentration of the heavy metals listed above. The mixture of the adsorbents on the column was replaced with a fresh one and sample $\mathrm{X}$ and $\mathrm{Y}$ was flown in that order through the adsorption column and the filtrate of each was collected at an interval of $2 \mathrm{~h}$ as well and analyzed. The process was repeated all over again using a particle size of $300 \mu$.

Figure 8 shows the adsorption column, where the four (4) adsorbents were mixed together to achieve simultaneous mixture as key part of the experimental work.

\section{Results and discussion}

The results presented in Tables 1, 2, 3 and 4 were obtained from the simultaneous mixture of the adsorbents used for the treatment of produced water samples $(\mathrm{R}, \mathrm{X}, \mathrm{Y})$ in the adsorption column. The results from each sample were for both 150 and $300 \mu$ particle size. The plots in Fig. 9 extracted from Table 1 were more of linear form showing that the more the contact time, the more the produced water sample loses its toxic metals. At $8 \mathrm{~h}$ with $150 \mu$ particles size, lead $(\mathrm{Pb})$, cadmium $(\mathrm{Cd})$, cupper $(\mathrm{Cu})$ and chromium (Cr) were all completely removed from the produced water sample. This means that $\mathrm{Pb}, \mathrm{Cd}, \mathrm{Cu}$ and $\mathrm{Cr}$ were reduced to zero from their raw values of $0.132,0.014$,

Table 1 Results of the concentrations (mg/L) of metals in sample R (Imo River sample) for simultaneous mixture

\begin{tabular}{|c|c|c|c|c|c|c|c|c|c|c|c|c|c|c|}
\hline Sample R & $\mathrm{pb}$ & $\mathrm{Ni}$ & $\mathrm{Cd}$ & $\mathrm{Cu}$ & $\mathrm{Fe}$ & $\mathrm{Mg}$ & $\mathrm{Cr}$ & $\mathrm{Zn}$ & Mn & $\mathrm{Ca}$ & $\mathrm{Ar}$ & B & Sn & $\mathrm{Ba}$ \\
\hline Raw & 0.132 & 0.036 & 0.014 & 0.076 & 0.552 & 3.699 & 0.071 & 0.125 & 0.062 & 430 & 4.65 & 1.59 & 0.155 & 0.038 \\
\hline \multicolumn{15}{|c|}{ After treatment with adsorbents using $150 \mu$ particles size } \\
\hline $2 \mathrm{~h}$ & 0.112 & 0.025 & 0.013 & 0.07 & 0.488 & 3.455 & 0.07 & 0.122 & 0.058 & 390 & 4.43 & 1.48 & 0.124 & 0.037 \\
\hline $4 \mathrm{~h}$ & 0.027 & 0.023 & 0.01 & 0.067 & 0.355 & 3.256 & 0.067 & 0.112 & 0.055 & 155 & 4.32 & 1.352 & 0.088 & 0.032 \\
\hline $6 \mathrm{~h}$ & 0.011 & 0.02 & 0.008 & 0.005 & 0.244 & 3.122 & 0.032 & 0.068 & 0.051 & 55 & 3.82 & 1.322 & 0.067 & 0.024 \\
\hline $8 \mathrm{~h}$ & ND & 0.017 & ND & ND & 0.078 & 2.965 & ND & 0.009 & 0.051 & 4.9 & 3.612 & 1.12 & 0.034 & 0.021 \\
\hline \multicolumn{15}{|c|}{ After treatment with adsorbents using $300 \mu$ particle size } \\
\hline $2 \mathrm{~h}$ & 0.132 & 0.034 & 0.013 & 0.076 & 0.451 & 3.655 & 0.071 & 0.122 & 0.061 & 360 & 4.62 & 1.577 & 0.154 & 0.036 \\
\hline $4 \mathrm{~h}$ & 0.131 & 0.034 & 0.011 & 0.073 & 0.422 & 3.522 & 0.068 & 0.122 & 0.055 & 211 & 4.61 & 1.572 & 0.152 & 0.036 \\
\hline $6 \mathrm{~h}$ & 0.131 & 0.003 & 0.01 & 0.071 & 0.312 & 3.234 & 0.066 & 0.111 & 0.053 & 44 & 4.61 & 1.571 & 0.139 & 0.032 \\
\hline $8 \mathrm{~h}$ & 0.13 & 0.001 & 0.004 & 0.063 & 0.311 & 2.011 & 0.066 & 0.013 & 0.04 & 1.3 & 4.58 & 1.571 & 0.133 & 0.031 \\
\hline
\end{tabular}


Table 2 Results of the concentrations (mg/L) of metals in sample X (Nembe sample) for simultaneous mixture

\begin{tabular}{|c|c|c|c|c|c|c|c|c|c|c|c|c|c|c|}
\hline Sample X & $\mathrm{pb}$ & $\mathrm{Ni}$ & $\mathrm{Cd}$ & $\mathrm{Cu}$ & $\mathrm{Fe}$ & $\mathrm{Mg}$ & $\mathrm{Cr}$ & $\mathrm{Zn}$ & Mn & $\mathrm{Ca}$ & $\mathrm{Ar}$ & $\mathrm{B}$ & Sn & $\mathrm{Ba}$ \\
\hline Raw & 0.078 & 0.026 & 0.007 & 0.07 & 0.783 & 5.106 & 0.121 & 0.163 & 0.071 & 390 & 5.544 & 2.151 & 0.144 & 0.045 \\
\hline \multicolumn{15}{|c|}{ After treatment with adsorbents using $150 \mu$ particles size } \\
\hline $2 \mathrm{~h}$ & 0.068 & 0.024 & 0.006 & 0.058 & 0.422 & 4.722 & 0.099 & 0.161 & 0.067 & 200 & 5.297 & 2.011 & 0.141 & 0.042 \\
\hline $4 \mathrm{~h}$ & 0.054 & 0.023 & 0.005 & 0.003 & 0.233 & 4.281 & 0.097 & 0.143 & 0.055 & 120 & 5.024 & 1.722 & 0.122 & 0.035 \\
\hline $6 \mathrm{~h}$ & 0.007 & 0.022 & 0.005 & 0.001 & 0.007 & 3.445 & 0.092 & 0.089 & 0.049 & 44 & 4.188 & 1.323 & 0.077 & 0.031 \\
\hline $8 \mathrm{~h}$ & ND & 0.022 & 0.004 & ND & 0.005 & 3.256 & 0.082 & 0.059 & 0.036 & 4.8 & 3.612 & 1.121 & 0.034 & 0.021 \\
\hline \multicolumn{15}{|c|}{ After treatment with adsorbents using $300 \mu$ particle size } \\
\hline $2 \mathrm{~h}$ & 0.074 & 0.026 & 0.007 & 0.068 & 0.544 & 4.721 & 0.121 & 0.161 & 0.069 & 250 & 5.542 & 2.151 & 0.142 & 0.043 \\
\hline $4 \mathrm{~h}$ & 0.058 & 0.024 & 0.006 & 0.052 & 0.038 & 3.223 & 0.098 & 0.098 & 0.057 & 120 & 5.412 & 2.101 & 0.133 & 0.043 \\
\hline $6 \mathrm{~h}$ & 0.033 & 0.023 & 0.006 & 0.041 & 0.023 & 2.101 & 0.094 & 0.095 & 0.053 & 70.52 & 4.231 & 2.005 & 0.127 & 0.041 \\
\hline $8 \mathrm{~h}$ & 0.023 & 0.023 & 0.005 & 0.024 & 0.016 & 1.401 & 0.091 & 0.095 & 0.039 & 1.41 & 3.822 & 1.994 & 0.127 & 0.035 \\
\hline
\end{tabular}

Table 3 Results of the concentrations ( $\mathrm{mg} / \mathrm{L}$ ) of the metals in sample Y (Kolo creek sample) for simultaneous mixture

\begin{tabular}{|c|c|c|c|c|c|c|c|c|c|c|c|c|c|c|}
\hline Sample Y & $\mathrm{pb}$ & $\mathrm{Ni}$ & $\mathrm{Cd}$ & $\mathrm{Cu}$ & $\mathrm{Fe}$ & $\mathrm{Mg}$ & $\mathrm{Cr}$ & $\mathrm{Zn}$ & $\mathrm{Mn}$ & $\mathrm{Ca}$ & $\mathrm{Ar}$ & B & $\mathrm{Sn}$ & $\mathrm{Ba}$ \\
\hline Raw & 0.192 & 0.231 & ND & 0.038 & 0.805 & 5.578 & 0.397 & 0.174 & 0.081 & 505 & 4.522 & 1.921 & 1.74 & 0.091 \\
\hline \multicolumn{15}{|c|}{ After treatment with adsorbents using $150 \mu$ particles size } \\
\hline $2 \mathrm{~h}$ & 0.188 & 0.189 & ND & 0.035 & 0.651 & 4.981 & 0.281 & 0.172 & 0.074 & 308 & 3.221 & 1.722 & 1.505 & 0.072 \\
\hline $4 \mathrm{~h}$ & 0.185 & 0.164 & ND & 0.033 & 0.362 & 3.554 & 0.179 & 0.158 & 0.058 & 150 & 2.792 & 1.441 & 1.449 & 0.058 \\
\hline $6 \mathrm{~h}$ & 0.171 & 0.124 & ND & 0.021 & 0.244 & 2.482 & 0.155 & 0.132 & 0.023 & 55.88 & 2.204 & 1.202 & 1.322 & 0.051 \\
\hline $8 \mathrm{~h}$ & 0.171 & 0.118 & ND & ND & 0.172 & 1.326 & ND & 0.112 & 0.019 & 1.11 & 1.678 & 1.142 & 1.228 & 0.045 \\
\hline \multicolumn{15}{|c|}{ After treatment with adsorbents using $300 \mu$ particle size } \\
\hline $2 \mathrm{~h}$ & 0.184 & 0.231 & ND & 0.037 & 0.755 & 5.499 & 0.395 & 0.173 & 0.075 & 300 & 4.442 & 1.898 & 1.722 & 0.085 \\
\hline $4 \mathrm{~h}$ & 0.066 & 0.188 & ND & 0.035 & 0.621 & 5.355 & 0.382 & 0.165 & 0.071 & 160 & 4.311 & 1.852 & 1.667 & 0.065 \\
\hline $6 \mathrm{~h}$ & 0.043 & 0.094 & ND & 0.031 & 0.433 & 3.221 & 0.341 & 0.122 & 0.055 & 40 & 3.311 & 1.733 & 1.552 & 0.032 \\
\hline $8 \mathrm{~h}$ & 0.008 & 0.028 & ND & ND & 0.291 & 0.244 & 0.332 & ND & ND & ND & 3.201 & 1.733 & 1.499 & ND \\
\hline
\end{tabular}

Table 4 Analysis of $\mathrm{Pb}$ (lead) using Langmuir and Freundlich models for simultaneous mixture of the adsorbents using sample $\mathrm{R}$

\begin{tabular}{lllrll}
\hline$t(\mathrm{~h})$ & $C_{\mathrm{e}}(\mathrm{mg} / \mathrm{L})$ & $q_{\mathrm{e}}(\mathrm{g} / \mathrm{L})$ & $C_{\mathrm{e}} / q_{\mathrm{e}}(\mathrm{g} / \mathrm{L})$ & $\begin{array}{l}\log C_{\mathrm{e}} \\
(\mathrm{mg} / \mathrm{L})\end{array}$ & $\log q_{\mathrm{e}}(\mathrm{g} / \mathrm{L})$ \\
\hline 2 & 0.112 & 0.000625 & 179.200 & -0.9508 & -3.2041 \\
4 & 0.027 & 0.00328 & 8.231 & -1.5686 & -2.4841 \\
6 & 0.011 & 0.00378 & 2.910 & -1.9586 & -2.4225 \\
8 & 0.000 & 0.00413 & 0.000 & 0.000 & -2.3840 \\
\hline
\end{tabular}

0.076 and $0.071-0.00 \mathrm{mg} / \mathrm{L}$ each. Other metals (nickel, iron, magnesium zinc, manganese, calcium, arsenic, boron and tin barium etc.) were as well reduced to the barest minimum beyond the regulatory limits as set by the regulatory bodies. The result obtained with the $300 \mu$ particle size as captured in Fig. 10 were equally good as the metals were all affected positively with respect to the reduction in their concentrations on the produced water. The metals were all reduced to allowable limits though none of them could be removed completely as can be seen when compared with $150 \mu$ particle size. This goes to show that in the adsorption process, contact time and particle size matter a lot as they are among the determining factors for effective and efficient adsorption process. The more the surface area of the adsorbents and the more the contact time, the better the adsorption process.

The plots (Fig. 11 from Table 2) are all linear with negative slopes; it shows that the more the contact time between the adsorbents and the produced water sample, the more the metal concentrations in the produced water go down. Lead $(\mathrm{Pb})$ and cupper $(\mathrm{Cu})$ were completely adsorbed from the sample after $8 \mathrm{~h}$ of treatment while other metals were positively affected but not completely removed. The metals removal depends on the activeness of the adsorbents. The more the availability of the surface of the adsorbents (adsorption sites) as a result of the large adsorption surface, the more the metals are adsorbed.

From the plots in Fig. 12 for $300 \mu$ size, very good results were also obtained just like that of $150 \mu$ particle size. The concentration of almost all the metals investigated were reduced to the barest minimum as required by the regulatory 
Fig. 9 Plot of conc. of $\mathrm{Pb}, \mathrm{Ni}, \mathrm{Cd}$ andCu versus time (sample $\mathrm{R}$, $150 \mu$ size)
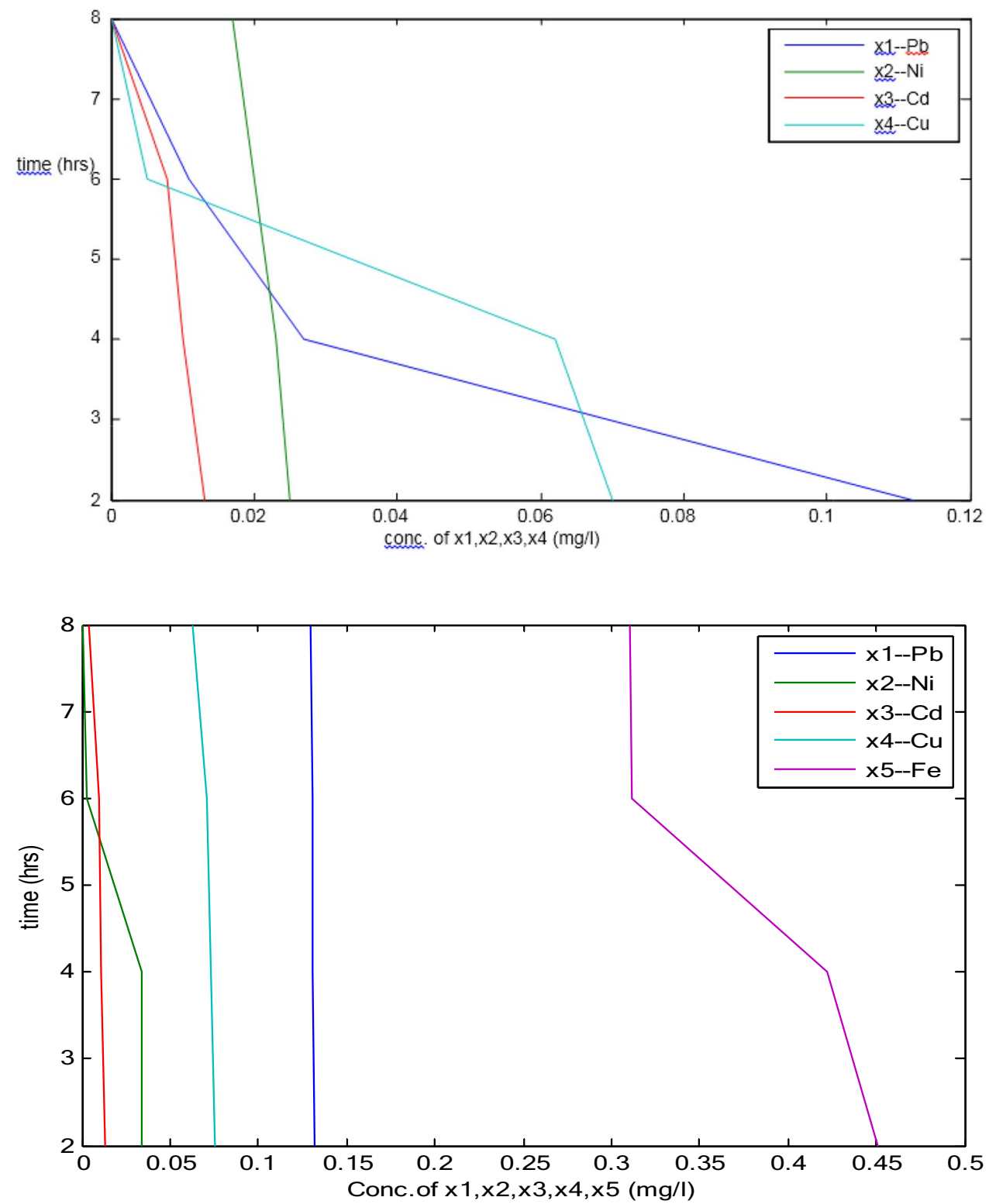

Fig. 10 Plot of conc. of $\mathrm{Pb}, \mathrm{Ni}$, $\mathrm{Cd}$ and $\mathrm{Cu}$ versus time (sample $\mathrm{R}, 300 \mu$ size) body though better results were obtained with $150 \mu$ size because of larger surface area.

The plots in Fig. 13 extracted from Table 3 were all linear with negative slopes; it shows that the more the contact time between the adsorbents and the produced water sample, the more the metal concentrations in the produced water drop. Cupper $(\mathrm{Cu})$ was found to be completely removed from the sample after $8 \mathrm{~h}$ of treatment. Based on observation, the produced water sample from Kolo creek oil field did not contain Cadmium at all. This could be as a result of the location of the field.

Figure 14 is a plot of $\mathrm{Pb}, \mathrm{Ni}, \mathrm{Cu}$ and $\mathrm{Fe}(\mathrm{mg} / \mathrm{L})$ against time (h) for $300 \mu$ particle size. The plots are linear with same negative slopes as the previous one of $150 \mu$ size. From the plots, cupper $(\mathrm{Cu})$ was completely removed from the sample after $8 \mathrm{~h}$ of treatment. $\mathrm{Zn}, \mathrm{Mn}, \mathrm{Ca}$ and $\mathrm{Ba}$ were also completely eliminated from the sample after $8 \mathrm{~h}$ of treatment according to Table 3 .

In summary it was observed that adsorption process is more favorable when the surface area of an adsorbent is large. The larger the surface areas, the smaller the particles and the more the adsorption sites for effective adsorption process. From the research, better results were obtained with $150 \mu$ size because of its large surface area compared with $300 \mu$ size. Simultaneous mixture of the adsorbents has proved worthwhile in the treatment of produced water from Niger Delta oil field. The results obtained were in accordance with the discharge limits as stated by the regulatory bodies. 
Fig. 11 Plot of conc. of $\mathrm{Pb}, \mathrm{Ni}$, $\mathrm{Cd}$ and $\mathrm{Cu}$ versus time (sample $\mathrm{X}, 150 \mu$ size)
Fig. 12 Plot of conc. of $\mathrm{Pb}, \mathrm{Ni}$, $\mathrm{Cd}$ and $\mathrm{Cu}$ versus time (sample $\mathrm{X}, 300 \mu$ size)
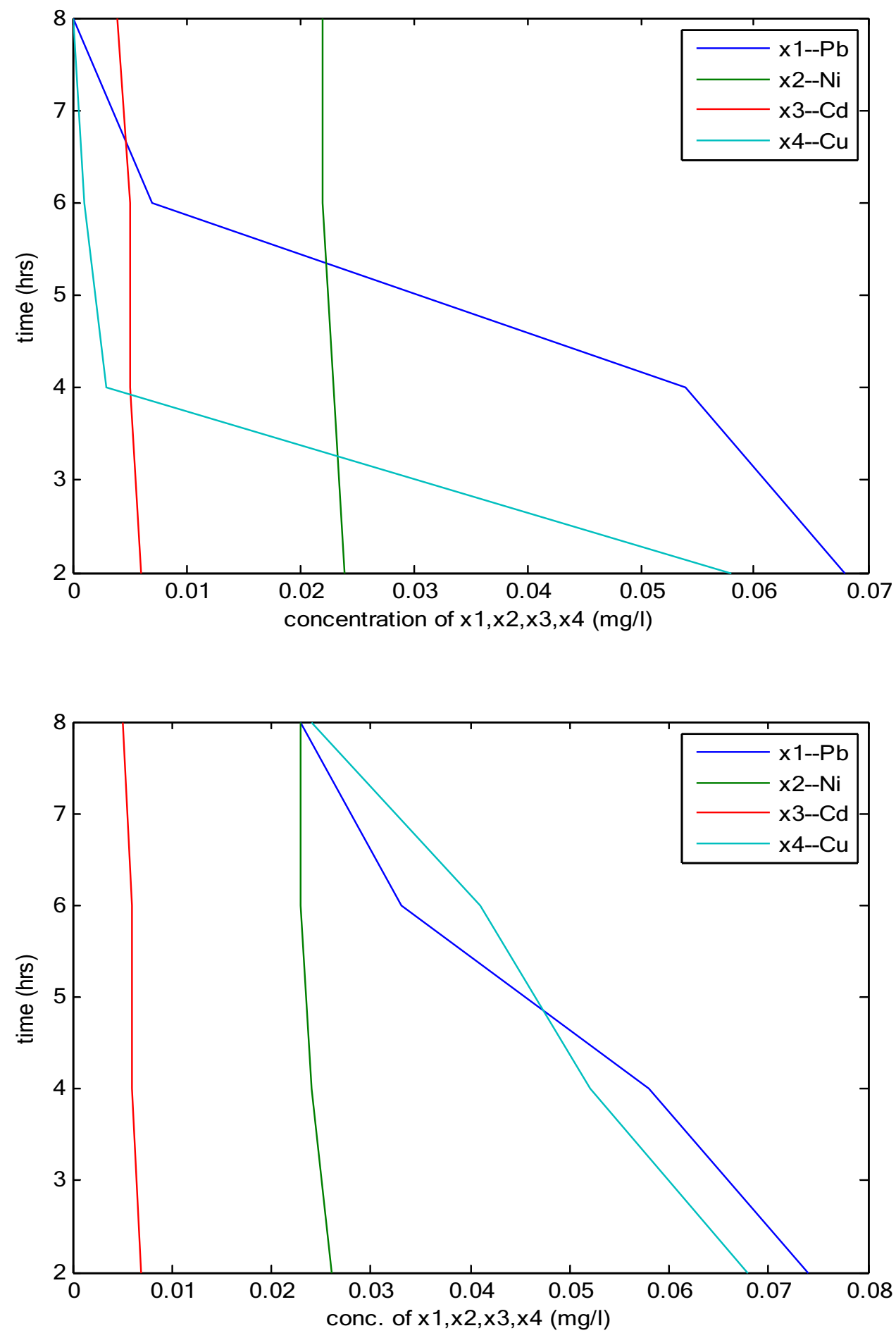

\section{Analysis of the results using adsorption isotherms}

\section{The Langmuir model}

This isotherm model is used to express the relationship that exists between the quantity of extracted material and its equilibrium concentration in bulk of solutions. Langmuir isotherm is only acceptable (valid) for monolayer adsorption on a surface containing finite number of similar sites. Langmuir isotherm model assumes a uniform adsorption on the surface and transmigration in the plane of the surface. Langmuir isotherm can be expressed as:

$q_{\mathrm{e}}=\left(K_{\mathrm{L}} C_{\mathrm{e}}\right) /\left(1+b C_{\mathrm{e}}\right)$ 
Fig. 13 Plot of conc. of $\mathrm{Pb}, \mathrm{Ni}$, $\mathrm{Cu}$ and $\mathrm{Fe}$ versus time (sample Y, $150 \mu$ size)
Fig. 14 Plot of conc. of $\mathrm{Pb}, \mathrm{Ni}$, $\mathrm{Cu}$ and $\mathrm{Fe}$ versus time (sample $\mathrm{Y}, 300 \mu$ particle size)
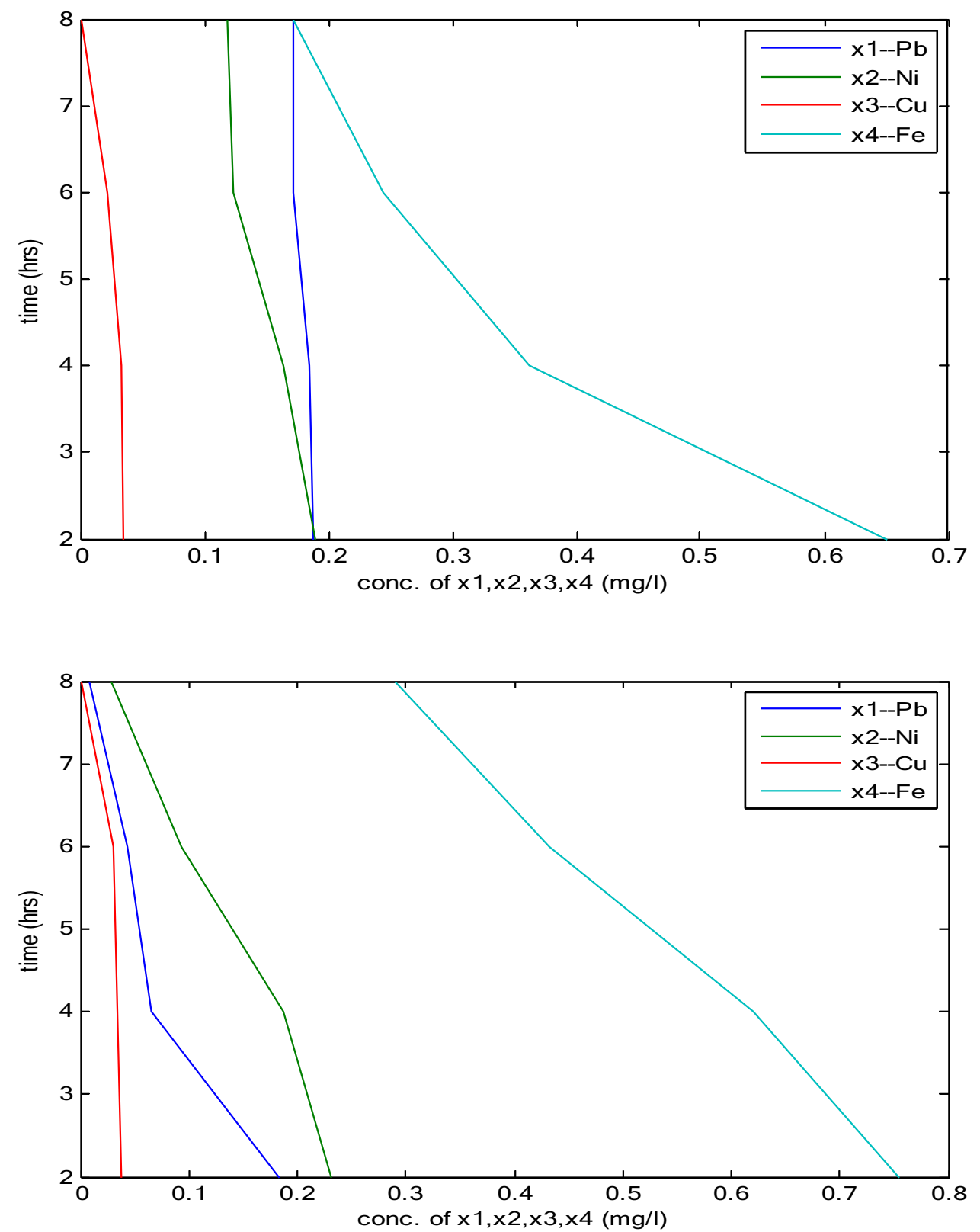

Table 5 Analysis of Ni (nickel) using Langmuir and Freundlich models for simultaneous mixture of the adsorbents using sample $\mathrm{R}$

\begin{tabular}{llllll}
\hline$t(\mathrm{~h})$ & $C_{\mathrm{e}}(\mathrm{mg} / \mathrm{L})$ & $q_{\mathrm{e}}(\mathrm{g} / \mathrm{L})$ & $C_{\mathrm{e}} / q_{\mathrm{e}}(\mathrm{g} / \mathrm{L})$ & $\begin{array}{l}\log C_{\mathrm{e}} \\
(\mathrm{mg} / \mathrm{L})\end{array}$ & $\log q_{\mathrm{e}}(\mathrm{g} / \mathrm{L})$ \\
\hline 2 & 0.025 & 0.000344 & 72.67 & -1.6020 & -3.4634 \\
4 & 0.023 & 0.000406 & 56.65 & -1.6383 & -3.3915 \\
6 & 0.020 & 0.000501 & 40.00 & -1.6989 & -3.3010 \\
8 & 0.017 & 0.000594 & 28.62 & -1.7696 & -3.2262 \\
\hline
\end{tabular}

where $q_{\mathrm{e}}$ is capacity of adsorption at equilibrium in $(\mathrm{mg} / \mathrm{g})$, $C_{\mathrm{e}}$ the equilibrium concentration $(\mathrm{mg} / \mathrm{L})$ and $K_{\mathrm{L}}$ is the Langmuir constant in $(\mathrm{mL} / \mathrm{mg})$ (Table 5$)$.

\section{The Freundlich model}

Freundlich isotherm model is a model that considers adsorption process to occur on heterogeneous surfaces; and the model further states that adsorption capacity is related to the concentration of the adsorbent in question. The Freundlich model can be expression as:

$q_{\mathrm{e}}=K_{\mathrm{F}}$

Note $K_{\mathrm{F}}$ is the Freundlich constant and $1 / n$ is a constant showing the reaction intensity. These Freundlich parameters $K_{\mathrm{F}}$ and $1 / n$ can be estimated graphically from the plot of 


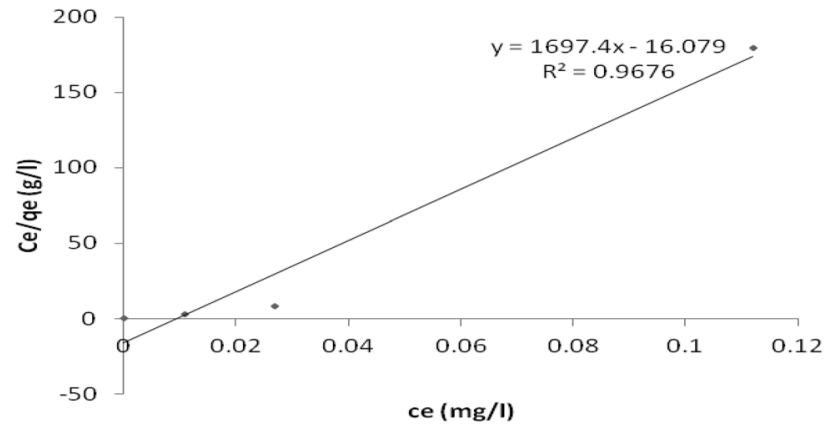

Fig. 15 Analysis of $\mathrm{Pb}$ using Langmuir isotherm for sample $\mathrm{R}$ revealed that the sorption of $\mathrm{Pb}$ ion on the simultaneous mixture of the adsorbents was found to be a favorable process. The correlation coefficient from Freundlich isotherm plot of $\log q_{\mathrm{e}}$ versus $\log c_{\mathrm{e}}$ as captured in Fig. 16 could not give a better result, showing that Freundlich sorption isotherm model is not suitable for equilibrium study of $\mathrm{Pb}$ (Fig. 17).

For the Ni adsorption, the linear plot of $\log q_{\mathrm{e}}$ versus $\log c_{\mathrm{e}}$ indicates that adsorption obeys the Freundlich sorption model as shown in Fig. 18. The values of $K_{\mathrm{F}}$ and $n$ were determined from the slope and intercept of the plot respectively as captured in Table 6 . The correlation coefficient $\left(R^{2}\right)$ was estimated to be 0.9835 . This shows that the
Table 6 A comparison of correlation coefficient and other parameters for the simultaneous mixture of the adsorbents with sample R using the two models

\begin{tabular}{|c|c|c|c|c|c|c|c|c|}
\hline \multirow[t]{2}{*}{ Metal } & \multicolumn{3}{|c|}{ Langmuir model } & \multicolumn{5}{|c|}{ Freundlich model } \\
\hline & $\overline{R^{2}}$ & $b$ & $K_{\mathrm{L}}$ & $R_{\mathrm{L}}$ & $Q_{\mathrm{o}}$ & $R^{2}$ & $n$ & $K_{\mathrm{F}}$ \\
\hline $\mathrm{Pb}$ & 0.97 & 1.75 & 0.00525 & 0.812 & 0.003 & 0.038 & 6.33 & 0.9932 \\
\hline $\mathrm{Ni}$ & 0.97 & 47.6 & 0.0099 & 0.369 & 0.00021 & 0.98 & 0.794 & 1.39 \\
\hline $\mathrm{Fe}$ & 0.74 & 15.5 & 0.00399 & 0.105 & 0.000258 & 0.87 & 2.64 & 0.993 \\
\hline
\end{tabular}

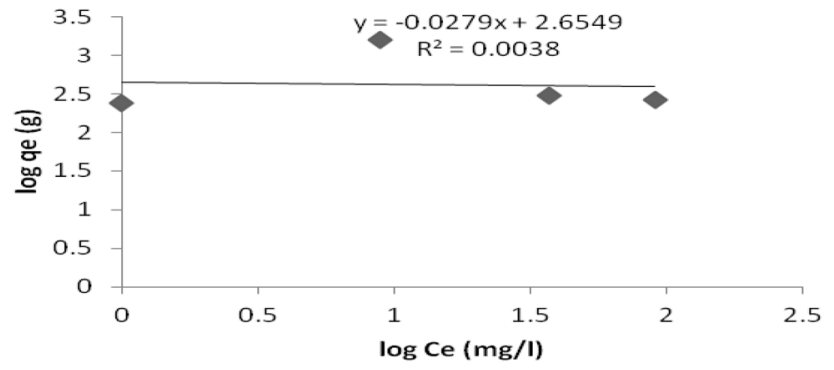

Fig. 16 Analysis of $\mathrm{Pb}$ using Freundlich isotherm for sample $\mathrm{R}$

experimental values and then applying the Freundlich equation in this form:

$\ln q_{\mathrm{e}}=\ln k_{\mathrm{F}}+(1 / n) \ln c_{\mathrm{e}}$

The linear plot of $c_{\mathrm{e}} / q_{\mathrm{e}}$ versus $c_{\mathrm{e}}$ indicates that adsorption process follows the Langmuir model as shown in Fig. 15. The values of $Q$ and $b$ were obtained from the slope and intercept of the plotted data in Table 6 . The correlation coefficient $\left(R^{2}\right)$ was found to be 0.9676 for $\mathrm{Pb}$ and 0.0038 for same $\mathrm{Pb}$ as captured in Fig. 16. The results revealed that the Langmuir sorption isotherm model is good for equilibrium study for $\mathrm{Pb}$. This suggests the formation of monolayer coverage of the adsorbate on the adsorbent surface for the metal ion.

The quantity of metal ion extracted per unit mass of the adsorbent rises with the metal concentration as expected and the sorption capacity was also determined. The value of the equilibrium separation factor RL, of 0.812 (Table 6)

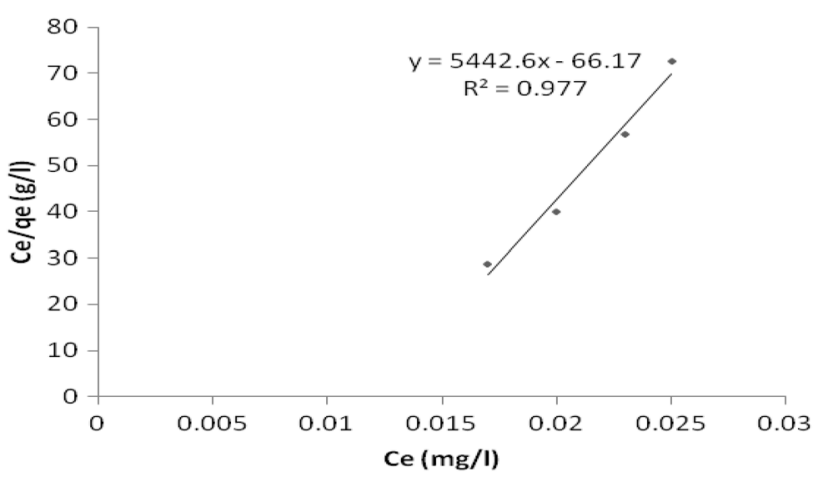

Fig. 17 Analysis of Ni using Langmuir isotherm for sample R

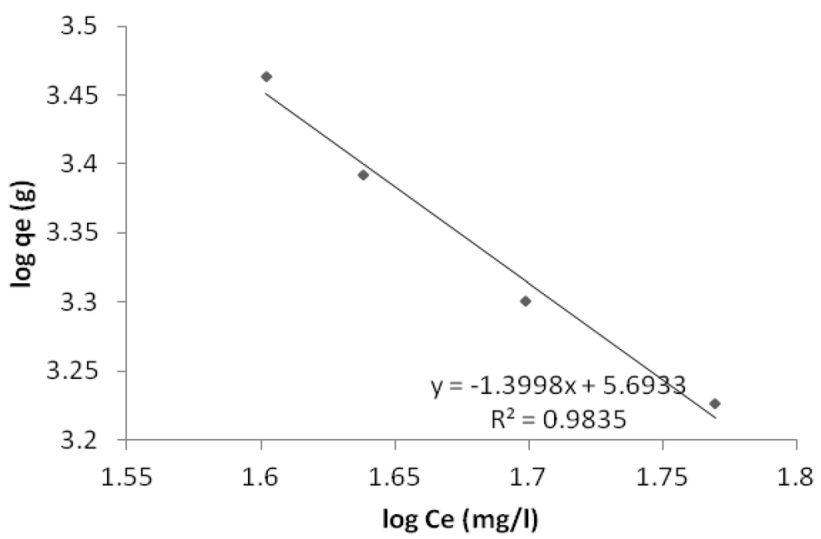

Fig. 18 Analysis of Ni using Freundlich isotherm for sample R 


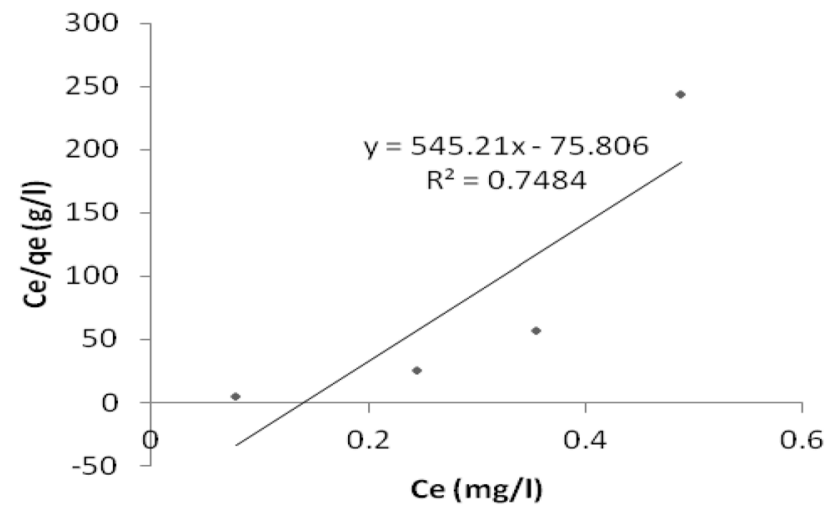

Fig. 19 Analysis of Fe using Langmuir isotherm for sample R

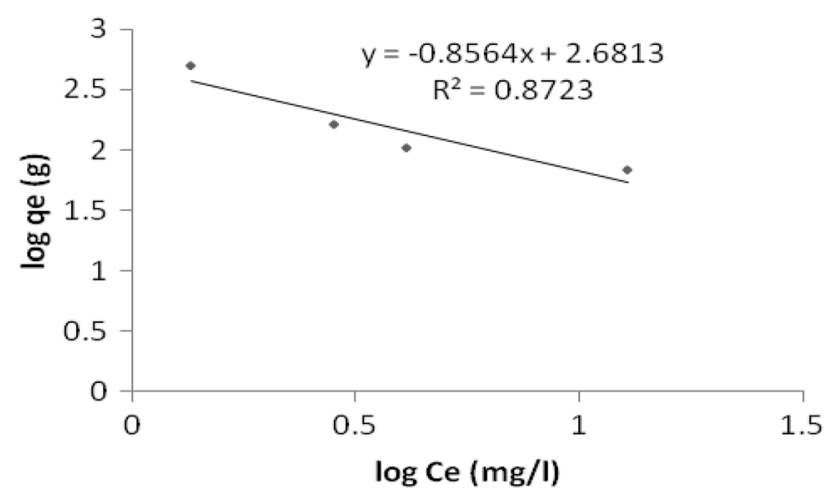

Fig. 20 Analysis of Fe using Freundlich isotherm for sample R

Freundlich sorption isotherm is good for equilibrium study of $\mathrm{Ni}$. This suggests the formation of heterogeneous layer coverage of the adsorbate on the adsorbent surface for the metal ion. The values of $K_{\mathrm{F}}$ and $n$ (Table 6) indicate the adsorption process is favorable. Although the Langmuir isotherm model result for $\mathrm{Ni}$ adsorption as captured in Fig. 17 indicated an increasing trend for $C_{\mathrm{e}} / q_{\mathrm{e}}(\mathrm{g} / \mathrm{L})$ versus $C_{\mathrm{e}}$, it was not a bad result; as fortunately, Freundlich model gave a better result with respect to $\mathrm{Ni}$ adsorption on the adsorbent surface.

For Fe (iron) adsorption on the simultaneous mixture of the adsorbents, Freundlich-type isotherm model gives a better result than Langmuir isotherm model. The plot of $\log q_{\mathrm{e}}$ versus $\log c_{\mathrm{e}}$ indicates that adsorption obeys the Freundlich adsorption model as captured in Fig. 20. The values of $K_{\mathrm{F}}$ and $n$ were calculated from the slope and intercept of the plotted data in Table 6 . The correlation coefficient $\left(R^{2}\right)$ was estimated as 0.8723 . This shows that the Freundlich sorption isotherm model is suitable for equilibrium study for $\mathrm{Fe}$, when compared with the value of $R^{2}(0.7484)$ on the Langmuir plot captured in Fig. 19. This suggests the formation of heterogeneous layer coverage of the adsorbate on the adsorbent surface for the metal ion. The values of $K_{\mathrm{F}}$ and $n$ as indicated on Table 6 indicate that the sorption of Fe on the adsorbent surface is a favorable process (Fig. 20).

\section{Conclusion}

In this work, an adsorption chamber was successfully designed and used for the treatment of the produced water samples from Niger Delta Oil fields and the adsorption of heavy metals were evaluated based on Langmuir and Freundlich models. Simultaneous mixture of the adsorbents was very effective in the treatment of the produced water samples.

Based on statistical analysis, for the $150 \mu$ size of sample $\mathrm{R}$, the percentage reductions for the metal concentrations $(\mathrm{Pb}, \mathrm{Ni}, \mathrm{Cd}, \mathrm{Cu}, \mathrm{Fe}, \mathrm{Mg}, \mathrm{Cr}, \mathrm{Zn}, \mathrm{Mn}, \mathrm{Ca}, \mathrm{Ar}, \mathrm{B}, \mathrm{Sn}$ and Ba) were found to be $100 \%, 52.7 \%, 100 \%, 100 \%, 85.87 \%$, $19.48 \%, 100 \%, 92.8 \%, 17.74 \%, 98.86 \%, 22.32 \%, 29.56 \%$, $78.06 \%$ and $44.74 \%$, respectively, while the reduction in $300 \mu$ size were $1.52 \%, 97.2 \%, 71.4 \%, 17.1 \%, 43.8 \%, 45.6 \%$, $7.04 \%, 89.6 \%, 35.4 \%, 99.6 \%, 0.0001 \%, 1.19 \%, 14.19 \%$ and $0.002 \%$, respectively. Hence, the finer adsorbents were more effective in reducing the presence of heavy metals in the treated produced water.

The concentration of most of the heavy metals in the water samples were reduced to an acceptable level for discharge; below the standard disposal level $(\mathrm{Ca}-200 \mathrm{mg} / \mathrm{L}$, $\mathrm{Ba}-0.01 \mathrm{mg} / \mathrm{L}, \mathrm{Sn}-0.04 \mathrm{mg} / \mathrm{L}, \mathrm{B}-1.0-0.5 \mathrm{mg} / \mathrm{L}$, $\mathrm{Ar}-5 \mathrm{mg} / \mathrm{L}, \mathrm{Mn}-0.02 \mathrm{mg} / \mathrm{L}, \mathrm{Zn}-1.0 \mathrm{mg} / \mathrm{L}$, $\mathrm{Cr}-0.02 \mathrm{mg} / \mathrm{L}, \mathrm{Mg}-60 \mathrm{mg} / \mathrm{L}, \mathrm{Fe}-1.0 \mathrm{mg} / \mathrm{L}$, $\mathrm{Cu}-0.02 \mathrm{mg} / \mathrm{L}, \mathrm{Cd}-0.01 \mathrm{mg} / \mathrm{L}, \mathrm{Ni}-0.03 \mathrm{mg} / \mathrm{L}$ and $\mathrm{Pb}-0.05 \mathrm{mg} / \mathrm{L}$.).

Few other metals were found to have raw values (concentration before treatment) less than the discharge limit which is a good development. This method of produced water treatment is strongly recommended for oil industry and other wastewater generating industries. The local materials (adsorbents) are readily available, very economical and are environmentally friendly.

\section{Recommendations}

Further study should look into modification of the bio-adsorbents to avoid early degradation with time. Degradation of the bio-adsorbents result to loss of active site and this leads to poor adsorption process.

Other waste materials apart from the ones used in this research should be look into to see how effective and efficient they could be in produced water treatment.

The scope of the particle size should be extended and the results compared with the ones used in this research work.

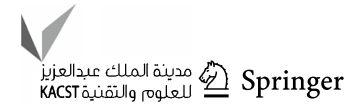


Research attention should be shifted from those conventional ways of produced water treatment. These conventional methods like micro filtration, precipitation, flotation and sedimentation, etc., are very capital intensive and pollute the environment. Researcher should be educated on the need to phase out these methods and imbibe the culture of using the locally and available adsorbent.

Acknowledgements The support of the laboratory staff of the Department of Petroleum Engineering, Afe Babalola University Ado-Ekiti, Ekiti state is acknowledged.

Funding Not applicable.

Open Access This article is licensed under a Creative Commons Attribution 4.0 International License, which permits use, sharing, adaptation, distribution and reproduction in any medium or format, as long as you give appropriate credit to the original author(s) and the source, provide a link to the Creative Commons licence, and indicate if changes were made. The images or other third party material in this article are included in the article's Creative Commons licence, unless indicated otherwise in a credit line to the material. If material is not included in the article's Creative Commons licence and your intended use is not permitted by statutory regulation or exceeds the permitted use, you will need to obtain permission directly from the copyright holder. To view a copy of this licence, visit http://creativecommons.org/licenses/by/4.0/.

\section{References}

Abdel-Aal HK, Mohamed A, Fahim MA (2003) Petroleum and gas field processing. King Fahd University of Petroleum and Minerals Dhahran, Saudi Arabia

Aclione A, Thyara CN, Mauricio I, Ramon L (2018) Produced water from oil: a review of the main treatment technologies. J Environ Chem 2(1):23-27

Ahalya R, Kanamadi D, Ramachandra TV (2005) Biosorption of $\mathrm{Cr}(\mathrm{VI})$ from aqueous solution by the husk bengal gram (Cicer arientinum). Environ J Biotechnol 8:258-264

Ahmed A, Taleb HI, Abdul SG, Mustafa IK, Hussain A (2016) Produced water treatment using naturally abundant pomegranate Peel. J Desalin Water Treat 57:6693-6701
Allen JS, Brown PA (2004) Isotherm analyses for single component and multi-component metal sorption onto lignite. J Chem Technol Biotechnol 62:17-24

Alzahrani S, Mohammad AW (2014) Challenges and trends in membrane technology implementation for produced water treatment: a review. J Water Process Eng 4:107-133

Annadural RS, Lee JD (2012) Adsorption of heavy metals from wastewater using banana and orange peels. Water Sci Technol $1: 185-190$

Dores R, Hussain A, Katebah M, Adham SS (2012) Using advanced water treatment technologies to treat produced water from the petroleum industry. In: SPE international production and operations conference and exhibition. Society of Petroleum Engineers

El-Din GA, Amer AA, Malsh G, Hussein M (2018) Study on the use of banana peels for oil spill removal. Alex Eng J 57(3):2061-2068

Fakhru'l-Razi A, Pendashteh A, Abdullah LC, Biak DRA, Madaeni SS, Abidin ZZ (2009) Review of technologies for oil and gas produced water treatment. J Hazard Mater 170(2-3):530-551

Gregory KB, Vidic RD, Dzombak DA (2011) Water management challenges associated with the production of shale gas by hydraulic fracturing. Elements 7(3):181-186

Igunnu ET, Chen GZ (2014) Produced water treatment technologies. Int J Low-Carbon Technol 9(3):157-177

Isehunwa SO, Onovae S (2011) Evaluation of produced water discharge in the Niger-Delta

Khaled O, El-Sayed M, El-Kady MY (2011) Treatment of oilwater emulsions by adsorption onto activated carbon, bentonite and deposited carbon. Egypt J Pet 20(2):9-15. https://doi. org/10.1016/j.ejpe.2011.06.002

Lu H, Liu YQ, Cai JB, Xu X, Xie LS, Yang Q et al (2019) Treatment of offshore oily produced water: Research and application of a novel fibrous coalescence technique. J Petrol Sci Eng 178:602-608

Rasheed T, Bilal M, Nabeel F, Adeel M, Iqbal HM (2019) Environmentally-related contaminants of high concern: potential sources and analytical modalities for detection, quantification, and treatment. Environ Int 122:52-66

Shah MT, Parmar HB, Rhyne LD, Kalli C, Utikar RP, Pareek VK (2019) A novel settling tank for produced water treatment: CFD simulations and PIV experiments. J Petrol Sci Eng 182:106352

Publisher's Note Springer Nature remains neutral with regard to jurisdictional claims in published maps and institutional affiliations. 